\title{
Evaluation of Dentofacial Changes Caused with Sabbagh Universal Spring in Mandibular Retrognathic Patients: A Pilot Study
}

\author{
Uyanlar A, Nalbantgil D* and Arun T
}

Dental Faculty, Yeditepe University, Turkey

\begin{abstract}
This pilot study was done to evaluate the dentofacial changes induced by the sabbagh universal spring (sus2) used in mandibular retrognathic patients. The study was carried out on 54 lateral cephalometric radiograms taken before placement and after removal of sus2 in the treatment group and at the beginning and six months after in the control group. The patient selection criteria were as follows: skeletal and dental class ii malocclusion due to retrognathic mandible, normal or low-angle growth pattern, post-peak growth period and no extracted or congenitally missing permanent teeth. The statistical evaluation of the data suggested the following results: no significant sagittal and vertical skeletal changes were observed. The slight retrusion and extrusion of the maxillary incisors as well as the distinct protrusion and intrusion of mandibular incisors were found to be statistically significant. The occlusal plane rotated in clockwise direction as a result of these dentoalveolar changes. Overbite and overjet were reduced significantly in all patients. The changes related to soft tissue profile were limited. The correction of class ii malocclusion by sus ${ }^{2}$ appliance in late-adolescence was achieved by only dentoalveolar changes. Thus, it can be an acceptable substitute to class ii elastics for noncompliant patients.
\end{abstract}

Keywords: Adolescence; Dentofacial orthopedics; Functional therapy; Retrusion; Sabbagh Universal Spring $\left(\right.$ SUS $^{2}$ )

\section{Introduction}

Skeletal Class II malocclusion is considered to be the most frequent jaw discrepancy encountered in orthodontics [1]. In addition, McNamara [2] and Bass [3] reported mandibular retrognathia as the most common characteristic of Class II malocclusion rather than maxillary protrusion or a combination of both. When correcting mandibular deficiency, a problem based treatment plan should be done in order to obtain an esthetic facial profile as well as an appropriate dental occlusion. The required advancement that should be done accordingly can be accomplished by stimulating or redirecting the growth of the mandible in a favorable way. Numerous fixed and removable functional appliances are presented in literature in order to achieve these changes in both dental and skeletal components. The effects of these appliances are mainly related to the technique of fabrication, construction bites, and hours of wear [4]. Among these factors compliance is one of the major requirements for the success of the therapy. A poor patient co-operation may cause poor treatment result together with a prolonged treatment time. Thus, recently clinicians and manufacturers have designed an increasing number of non-compliance fixed functional appliances.

One of these newly developed devices that do not necessitate patient co-operation is the Sabbagh Universal Spring (SUS ${ }^{2}$ ) (Dentaurum, Ispringen, Germany). It is a telescope unit with a spring for universal intermaxillary use. This appliance was designed as the combination of the two most prevalent ones, Herbst and Jasper Jumper, aiming to improve their favorable treatment outcome and to minimize their disadvantages. Even though many studies have proved the efficacy of the Herbst [5-7], disadvantages such as requirement of complex lab work, extensive chair time, tendency to breakage, and production of rigid forces [8-10] persuaded clinicians to seek for alternatives. Jasper Jumper is another functional appliance, which keeps the mandible in a protruded position by applying continuous, light forces that enables patients' toleration [11]. On the other hand, since it does not provide rigid forces like Herbst, the skeletal effects obtained are limited [12-14]. Therefore, SUS ${ }^{2}$ appliance was designed by taking these favorable and unfavorable effects into consideration.

The primary advantage of SUS ${ }^{2}$ is that, in correction of Class II malocclusions it acts like Herbst, headgear or Class II elastics according to how it is activated. It produces constant, mainly horizontal forces when the mouth is closed. Also, it helps to avoid extractions and orthognathic operations [15]. Although this appliance offers numerous favorable advantages for the clinicians, the effects on dentofacial structures have not been documented yet.

The purpose of this clinical pilot study was to investigate the skeletal effect of the SUS ${ }^{2}$ appliance on dental, skeletal, and soft tissues in late adolescent patients with mandibular retrognathia.

\section{Materials and Methods}

\section{Sample}

This prospective study consisted of 27 patients (15 treated, 12 untreated) with skeletal and dental Class II malocclusion (Figures 1 and 2). The criteria for patient selection were:

- Skeletal and dental Class II malocclusion due to mandibular retrognathie (SNB angle $<80$ );

- Normal or low-angle growth pattern (SN-MP angle $\leq 32)$;

- Post-peak growth period;

- No extracted or congenitally missing permanent teeth.

- Minimum crowding in the lower dental arch.

The study was approved by the Yeditepe University Ethical Committee.

${ }^{*}$ Corresponding author: Didem Nalbantgil, Associate Professor, Dental Faculty, Yeditepe University, Turkey, Tel: +902163636044; Fax: +902163636211; E-mail: didem.nalbantgil@yeditepe.edu.tr

Received April 02, 2014; Accepted May 11, 2014; Published May 13, 2014

Citation: Uyanlar A, Nalbantgil D, Arun T (2014) Evaluation of Dentofacial Changes Caused with Sabbagh Universal Spring in Mandibular Retrognathic Patients: A Pilot Study. Dentistry 4: 237. doi:10.4172/2161-1122.1000237

Copyright: $\odot 2014$ Uyanlar A, et al. This is an open-access article distributed under the terms of the Creative Commons Attribution License, which permits unrestricted use, distribution, and reproduction in any medium, provided the original author and source are credited. 




Figure 1: Intraoral photos taken at the start of the treatment.

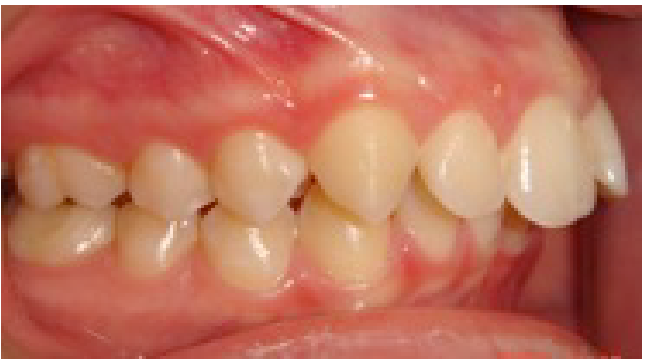

Figure 2: Intraoral photos taken at the start of the treatment.

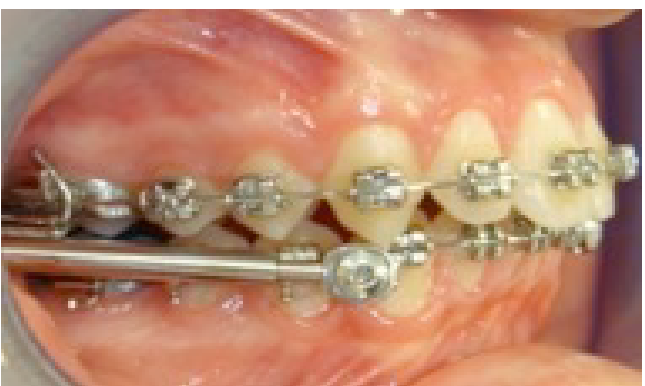

Figure 3: The application of SUS ${ }^{2}$ in the mouth.

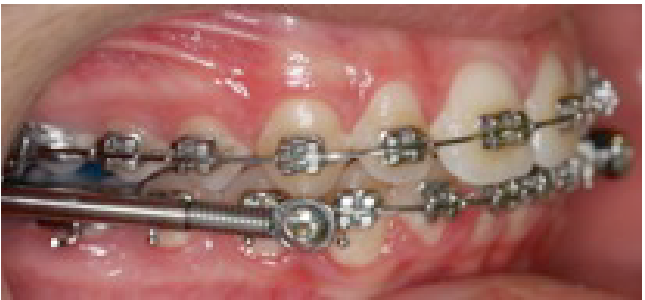

Figure 4: Intraoral photo taken at end of the SUS² therapy.
Cervical vertebrae maturation index (CVMI) was used for selecting the patients, and CVMI 5 and CVMI 6 stages which correspond to postpeak growth period was defined by lateral cephalometric radiographs. The mean pretreatment chronological ages were 15 years 2 months and 14 years 1 month for the treatment group and control group, respectively. The age range and the sex distribution of treatment and control groups are shown in Table 1.

\section{Appliance Design and Application}

In the SUS ${ }^{2}$ group, straight wire brackets were used and bands were placed with a transpalatal arch in the upper jaw to increase stability. After leveling, $0.019 \times 0.025$ inch stainless steel continuous arch wires were inserted and cinched back in the upper and lower arches before placing the appliances. According to the manufacturer's instructions, the one universal sized SUS ${ }^{2}$ was applied to the headgear tube of the upper first molar and to the lower arch, between the first premolar and the canine (Figure 3).

In order to obtain a rigid telescope effect, the spring force was minimized by inserting and turning the middle telescope tube into the guide tube (unscrew the slotted screw anticlockwise with the activation screw) as described by Sabbagh [15]. The patients were seen every 4 weeks and the appliances were activated every eight weeks by a piece of spacer (closed) spring, with steps not exceeding $5 \mathrm{~mm}$. The appliance was removed when a Class I or edge-to-edge overcorrection was achieved which eventuated in a mean time of 5.2 months (Figure 4).

If the patient reported any soft tissue irritation due to the appliance during opening and closing or chewed on the appliance, adjustment of the appliance was done by changing the position of the distal end of the pin.

\section{Cephalometric Methods}

Our study was carried out on 54 lateral cephalometric films that were taken before placement and after removal of the SUS ${ }^{2}$ appliance in the treatment group and at the beginning and six months after in the control group. The pretreatment and posttreatment cephalograms of each patient were traced manually on acetate paper consecutively by one examiner to minimize any possible method error, and 35 cephalometric landmarks were identified as seen in Table 2. The horizontal (RL1) and vertical (RL2) reference lines used in this study were also has been used by other investigators [16-19].

\section{Statistical Methods}

All statistical calculations were performed with NCSS 2007 software for Windows. The nonparametric Wilcoxon signed rank test was used to evaluate the differences in each group whereas; Mann-Whitney $U$-test was used to assess the differences between the groups. A confidence level greater than $5 \%$ was considered statistically not significant.

\begin{tabular}{|c|c|c|c|c|c|}
\hline Treatment Group & $\mathbf{n}$ & Mean & Standard Deviation & Minimum & Maximum \\
\hline Female & 8 & 14 years 8 months & 1 year 2 months & 13 years & 16 years 2 month \\
\hline Male & 7 & 15 years 6 months & 1 year 1 months & 14 years 4 month & 16 years 8 months \\
\hline Total & 15 & 15 years 2 month & 1 year 1 months & 13 years & 16 years 8 months \\
\hline \multicolumn{6}{|l|}{ Control Group } \\
\hline Female & 9 & 14 years 6 months & 1 year 5 months & 13 years & 16 years 10 months \\
\hline Male & 3 & 14 years 4 months & 1 year & 13 years 8 months & 15 years 1 month \\
\hline Total & 12 & 14 years 1 month & 1 year 5 months & 13 years & 16 years 10 months \\
\hline
\end{tabular}

$n$ indicates the number of patients

Table 1: Age Range and Sex Distribution of Treatm 'ent and Control Groups. 


\begin{tabular}{|c|c|c|}
\hline & Abbreviation & Definition \\
\hline 1 & SNA $\left({ }^{\circ}\right)$ & The angle between the lines Sella-Nasion and Nasion-A point \\
\hline 2 & $\operatorname{SNB}\left({ }^{\circ}\right)$ & The angle between the lines Sella-Nasion and Nasion-B point \\
\hline 3 & ANB $\left({ }^{\circ}\right)$ & The angle between the lines A point-Nasion and Nasion-B point \\
\hline 4 & SN/PP $\left({ }^{\circ}\right)$ & The angle between the lines Sella-Nasion and Palatal Plane (ANS-PNS) \\
\hline 5 & SN/MP $\left({ }^{\circ}\right)$ & The angle between the lines Sella-Nasion and Mandibular Plane (Me-Go) \\
\hline 6 & $\mathrm{SE}(\mathrm{mm})$ & The distance between Sella and E point \\
\hline 7 & $\mathrm{SL}(\mathrm{mm})$ & The distance between Sella and L point \\
\hline 8 & $\mathrm{Pg}-\mathrm{NB}(\mathrm{mm})$ & The distance between Pogonion and Nasion-B point \\
\hline 9 & $\operatorname{Ar}-\mathrm{Pg}(\mathrm{mm})$ & The distance between Articulare and Pogonion \\
\hline 10 & A-RL2 (mm) & The distance between A point and Reference Line 2 \\
\hline 11 & B-RL2 (mm) & The distance between B point and Reference Line 2 \\
\hline 12 & A-RL1 (mm) & The distance between A point and Reference Line 1 \\
\hline 13 & ANS-Me/N-Me (\%) & The ratio between lower facial height and total facial height \\
\hline 14 & Jarabak Ratio (\%) & The ratio between posterior facial height (S-Go) and anterior facial height (N-Me) \\
\hline 15 & Gonial Ratio (\%) & The ratio between the upper and lower gonial angles \\
\hline 16 & S-Ar/Ar-Go (\%) & The ration between Sella-Articulare distance and Articulare-Gonion distance \\
\hline 17 & U1/SN $\left({ }^{\circ}\right)$ & The angle between the Sella-Nasion and the upper incisor axis \\
\hline 18 & $\operatorname{IMPA}\left({ }^{\circ}\right)$ & The angle between the Mandibular Plane (Me-Go) and the lower incisor axis \\
\hline 19 & L1/RL2 $\left({ }^{\circ}\right)$ & The angle between the lower incisor axis and Reference Line 2 \\
\hline 20 & Interincisal Angle $\left({ }^{\circ}\right)$ & The angle between the upper incisor axis and the lower incisor axis \\
\hline 21 & $\mathrm{SN} / \mathrm{OP}\left({ }^{\circ}\right)$ & The angle between the Sella-Nasion and the Occlusal Plane \\
\hline 22 & L1/NB (mm) & The distance from the lower incisor most buccal point to the Nasion-B point \\
\hline 23 & Overjet (mm) & The distance from the lower incisor to upper incisor tips on the sagital plane \\
\hline 24 & Overbite (mm) & The distance from the lower incisor to upper incisor tips on the vertical plane \\
\hline 25 & U6-RL1 (mm) & The distance from the mesio-buccal cusp tip of upper first molar to Reference Line 1 \\
\hline 26 & U1-RL1 (mm) & The distance from the upper incisor tip to Reference Line 1 \\
\hline 27 & H Angle $\left({ }^{\circ}\right)$ & The angle between Nasion-B point and soft tissue pogonion - upper lip \\
\hline 28 & Nasolabial Angle $\left({ }^{\circ}\right)$ & The angle between nose tip - subnasale and subnasale - upper lip \\
\hline 29 & $\mathrm{~N}-\mathrm{A}-\mathrm{Pg}\left({ }^{\circ}\right)$ & The angle between Nasion - A point and A point - pogonion \\
\hline 30 & A-labialis superior $(\mathrm{mm})$ & The distance between A point and upper lip \\
\hline 31 & E line-labialis superior ( $\mathrm{mm}$ ) & The distance between upper lip and E Line (Soft tissue pogonion - nose tip) \\
\hline 32 & E line-labialis inferior $(\mathrm{mm})$ & The distance between lower lip and E Line (Soft tissue pogonion - nose tip) \\
\hline 33 & Labialis superior-RL2 (mm) & The distance between upper lip and Reference Line 2 \\
\hline 34 & Labialis inferior-RL2 (mm) & The distance between lower lip and Reference Line 2 \\
\hline 35 & Lip strength (mm) & $\begin{array}{l}\text { The difference between the distance from the most buccal point of upper incisor to upper lip and the distance from A point } \\
\text { to soft tissue sulcus superior }\end{array}$ \\
\hline
\end{tabular}

Table 2: Summary of Cephalometric Landmarks and Definitions.

In order to assess the magnitude of the method error, 20 randomly selected cephalograms were traced and measured again by the same examiner after an interval of 20 days. The method error was measured with correlation coefficients and no statistically significant method error was observed.

\section{Results}

\section{Skeletal Changes}

Statistical comparisons of pretreatment and posttreatment values of the groups are shown in Tables 3-5. In the control group, SNA shows no significant change (Table 3$)$ whereas; a limited decrease $\left(-0.9^{\circ}, p<0.05\right)$ was present in the treatment group (Table 4 ). When the two groups were compared, no significant change in SNA was found as seen in Table 5. Likewise maxilla, even though some minor changes were observed due to the appliance wear no significant sagittal and vertical changes were found in the mandible (Table 5). In the control group although limited differences related to growth were observed at SN/MP angle, Ar-Pg length, Jarabak, and S-Ar/Ar-Go ratio, these were found statistically not significant when two groups were compared. Comparisons of the cephalometric measurements of the control and treatment groups revealed that the appliance had no skeletal effect.

\section{Dental Changes}

In the control group no significant dental changes were observed (Table 3), whereas the differences related to SUS ${ }^{2}$ treatment were evident (Table 4 ). The upper incisors were significantly retroclined (U1/ $\mathrm{SN}:-3.7^{\circ}, p<0.01$ ) and extruded (U1-RL1: $1.15 \mathrm{~mm}, p<0.01$ ), while the lower incisors proclined (IMPA: $5.63^{\circ}, p<0.01$ ). The differences occurred relative to reference lines and at L1-NB distance confirmed this distinct protrusion (L1-NB: $1.63 \mathrm{~mm}, p<0.01$; L1/RL2: $6^{\circ}, p<0.01$ ). The overjet and overbite were improved as a consequence of upper incisors retroclination and lower incisors proclination.

In the treatment group besides these changes at the anterior region, a significant decrease (U6-RL1: $-0.78 \mathrm{~mm}, \mathrm{p}<0.01$ ) was observed at the distance between the upper molar and RL1 that revealed a minor intrusion of these teeth. The combination of these posterior and anterior dentoalveolar changes occurred in both jaws produced a $2.97^{\circ}$ clockwise rotation of the occlusal plane (Table 4). 


\begin{tabular}{|c|c|c|c|c|c|c|c|c|}
\hline & & & & Pos & ent & & & Wilcoxon \\
\hline & & Mean & SD & Mean & SD & Mean & SD & $P$ \\
\hline 1 & $\operatorname{SNA}\left({ }^{\circ}\right)$ & 81.58 & 2.44 & 81.5 & 2.93 & -0.08 & 1.68 & \\
\hline 2 & $\operatorname{SNB}\left({ }^{\circ}\right)$ & 76.08 & 3.04 & 76.63 & 3.1 & 0.54 & 1.14 & \\
\hline 3 & ANB $\left({ }^{\circ}\right)$ & 5.50 & 1.91 & 4.88 & 2.66 & -0.63 & 1.09 & \\
\hline 4 & SN/PP $\left({ }^{\circ}\right)$ & 9.63 & 3.22 & 9 & 2.35 & -0.63 & 1.26 & \\
\hline 5 & SN/MP $\left({ }^{\circ}\right)$ & 31.04 & 3.43 & 30.08 & 3.69 & -0.96 & 1.68 & * \\
\hline 6 & $\mathrm{SE}(\mathrm{mm})$ & 20.53 & 2.77 & 20.16 & 2.66 & -0.37 & 0.91 & \\
\hline 7 & $\mathrm{SL}(\mathrm{mm})$ & 45.44 & 6.68 & 46.65 & 7.06 & 1.21 & 2.36 & \\
\hline 8 & $\mathrm{Pg}-\mathrm{NB}(\mathrm{mm})$ & 3.05 & 2.15 & 3.12 & 2.04 & 0.06 & 0.35 & \\
\hline 9 & $\operatorname{Ar}-\mathrm{Pg}(\mathrm{mm})$ & 97.49 & 5.9 & 98.23 & 5.64 & 0.74 & 1 & * \\
\hline 10 & A-RL2 (mm) & 64.73 & 3.73 & 65.13 & 4.28 & 0.4 & 1.48 & \\
\hline 11 & B-RL2 (mm) & 55.83 & 5.24 & 56.7 & 5.46 & 0.87 & 1.74 & \\
\hline 12 & A-RL1 (mm) & 47.03 & 2.94 & 46.37 & 2.92 & -0.66 & 1.1 & \\
\hline 13 & ANS-Me/N-Me (\%) & 0.539 & 0.022 & 0.543 & 0.016 & 0 & 0.01 & \\
\hline 14 & Jarabak Ratio (\%) & 0.65 & 0.04 & 0.66 & 0.03 & 0.01 & 0.01 & * \\
\hline 15 & Gonial Ratio(\%) & 0.72 & 0.04 & 0.72 & 0.05 & 0 & 0.02 & \\
\hline 16 & S-Ar/Ar-Go (\%) & 0.81 & 0.08 & 0.78 & 0.08 & -0.03 & 0.03 & * \\
\hline 17 & U1/SN $\left({ }^{\circ}\right)$ & 100.04 & 8.31 & 101.12 & 7.57 & 1.08 & 3.52 & \\
\hline 18 & $\operatorname{IMPA}\left({ }^{\circ}\right)$ & 98.96 & 6.63 & 99 & 5.79 & 0.04 & 2.38 & \\
\hline 19 & $\operatorname{L1/RL2}\left({ }^{\circ}\right)$ & 32.71 & 7.58 & 31.96 & 6.87 & -0.75 & 2.4 & \\
\hline 20 & Interincisal Angle $\left(^{\circ}\right)$ & 130.5 & 9.56 & 130.12 & 8.93 & -0.38 & 2.92 & \\
\hline 21 & SN/OP $\left({ }^{\circ}\right)$ & 16.33 & 6.07 & 15.33 & 5.3 & -1 & 2.56 & \\
\hline 22 & L1/NB (mm) & 4.08 & 1.86 & 4.05 & 1.84 & -0.03 & 0.66 & \\
\hline 23 & U6-RL1 (mm) & 62.72 & 2.48 & 62.76 & 2.62 & 0.04 & 0.97 & \\
\hline 24 & U1-RL1 (mm) & 68.23 & 2.36 & 68.56 & 2.95 & 0.33 & 1.34 & \\
\hline 25 & Overjet (mm) & 2.9 & 1.65 & 2.83 & 1.62 & -0.07 & 0.88 & \\
\hline 26 & Overbite $(\mathrm{mm})$ & 4.83 & 1.31 & 4.76 & 1.28 & -0.06 & 0.41 & \\
\hline 27 & H Angle $\left({ }^{\circ}\right)$ & 10.75 & 4.05 & 10.29 & 3.91 & -0.46 & 2.78 & \\
\hline 28 & Nasolabial Angle $\left({ }^{\circ}\right)$ & 125.88 & 12.06 & 125.21 & 11.88 & -0.67 & 4.05 & \\
\hline 29 & N-A-Pg $\left(^{\circ}\right)$ & 172.17 & 6.71 & 173.25 & 7.39 & 1.08 & 2.07 & \\
\hline 30 & A-labialis superior $(\mathrm{mm})$ & 20.08 & 2.08 & 20.85 & 1.97 & 0.77 & 1.31 & \\
\hline 31 & E line-labialis superior $(\mathrm{mm})$ & -4.23 & 1.14 & -4.3 & 1.24 & -0.07 & 0.91 & \\
\hline 32 & E line-labialis inferior $(\mathrm{mm})$ & -3.2 & 1.3 & -3.35 & 1.49 & -0.15 & 0.51 & \\
\hline 33 & Labialis superior-RL2 (mm) & 79.04 & 5.32 & 80.15 & 5.76 & 1.11 & 1.65 & \\
\hline 34 & Labialis inferior-RL2 (mm) & 74.94 & 5.08 & 76.18 & 5.02 & 1.24 & 1.52 & * \\
\hline 35 & Lip strength (mm) & 1.01 & 3.33 & 0.67 & 3.41 & -0.34 & 1.54 & \\
\hline
\end{tabular}

Table 3: Changes and Comparisons of Pre- and Post-Six Month Interval Values within the Control Group

\begin{tabular}{|c|c|c|c|c|c|c|c|c|}
\hline & & & & & & & & Wilcoxon \\
\hline & & Mean & SD & Mean & SD & Mean & SD & $P$ \\
\hline 1 & SNA $\left({ }^{\circ}\right)$ & 80.27 & 3.73 & 79.37 & 3.54 & -0.9 & 1.43 & * \\
\hline 2 & SNB $\left({ }^{\circ}\right)$ & 75.53 & 4.2 & 76.17 & 4.38 & 0.63 & 1.23 & \\
\hline 3 & ANB $\left({ }^{\circ}\right)$ & 4.80 & 1.77 & 3.47 & 1.9 & -1.33 & 1.08 & ** \\
\hline 4 & SN/PP $\left({ }^{\circ}\right)$ & 9.83 & 3.36 & 10.33 & 2.7 & 0.5 & 2.6 & \\
\hline 5 & SN/MP $\left(^{\circ}\right)$ & 32.73 & 5.65 & 32.4 & 5.69 & -0.33 & 0.94 & \\
\hline 6 & $\mathrm{SE}(\mathrm{mm})$ & 20.35 & 3.07 & 20.51 & 3.02 & 0.17 & 1.15 & \\
\hline 7 & $\mathrm{SL}(\mathrm{mm})$ & 45.01 & 9.46 & 45.71 & 8.9 & 0.7 & 1.88 & \\
\hline 8 & Pg-NB (mm) & 3.91 & 1.64 & 3.82 & 1.57 & -0.09 & 0.8 & \\
\hline 9 & Ar-Pg (mm) & 99.19 & 6.94 & 100.73 & 7.5 & 1.54 & 1.97 & * \\
\hline 10 & A-RL2 (mm) & 63.93 & 4.8 & 63.95 & 5.11 & 0.03 & 1.28 & \\
\hline 11 & B-RL2 (mm) & 54.91 & 7.76 & 56.32 & 7.42 & 1.41 & 1.54 & ** \\
\hline 12 & A-RL1 (mm) & 48.36 & 4.03 & 48.66 & 4.22 & 0.3 & 1.81 & \\
\hline 13 & ANS-Me/N-Me (\%) & 0.54 & 0.024 & 0.537 & 0.023 & 0 & 0.01 & \\
\hline 14 & Jarabak Ratio (\%) & 0.67 & 0.08 & 0.66 & 0.05 & 0 & 0.05 & \\
\hline 15 & Gonial Ratio(\%) & 0.71 & 0.06 & 0.71 & 0.06 & 0 & 0.01 & \\
\hline 16 & S-Ar/Ar-Go (\%) & 0.78 & 0.1 & 0.75 & 0.1 & -0.03 & 0.06 & * \\
\hline 17 & U1/SN $\left({ }^{\circ}\right)$ & 104.43 & 5.38 & 100.73 & 7.22 & -3.70 & 3.63 & ** \\
\hline
\end{tabular}




\begin{tabular}{|c|c|c|c|c|c|c|c|c|}
\hline 18 & $\operatorname{IMPA}\left({ }^{\circ}\right)$ & 98.9 & 7.63 & 104.53 & 7.57 & 5.63 & 3.67 & ** \\
\hline 19 & L1/RL2 $\left(^{\circ}\right)$ & 34.27 & 6.4 & 40.27 & 5.91 & 6 & 4.22 & ** \\
\hline 20 & Interincisal Angle $\left({ }^{\circ}\right)$ & 124.3 & 7.43 & 122.53 & 6.71 & -1.77 & 5.61 & \\
\hline 21 & SN/OP $\left({ }^{\circ}\right)$ & 18.43 & 4.87 & 21.4 & 5.42 & 2.97 & 2.61 & ** \\
\hline 22 & L1/NB (mm) & 5.03 & 1.77 & 6.65 & 1.5 & 1.63 & 1.02 & ** \\
\hline 23 & U6-RL1 (mm) & 62.86 & 5.35 & 62.08 & 5.47 & -0.78 & 0.6 & ** \\
\hline 24 & U1-RL1 (mm) & 70.26 & 4.7 & 71.4 & 4.76 & 1.15 & 0.72 & ** \\
\hline 25 & Overjet (mm) & 5.84 & 1.67 & 2.11 & 0.8 & -3.73 & 1.89 & ** \\
\hline 26 & Overbite (mm) & 4.1 & 0.96 & 2.24 & 0.9 & -1.86 & 0.94 & ** \\
\hline 27 & H Angle $\left({ }^{\circ}\right)$ & 13.43 & 4.45 & 12.03 & 5.02 & -1.4 & 3.85 & * \\
\hline 28 & Nasolabial Angle $\left({ }^{\circ}\right)$ & 123.73 & 9.82 & 124.57 & 9.5 & 0.83 & 5.08 & \\
\hline 29 & N-A-Pg $\left(^{\circ}\right)$ & 174.03 & 5.24 & 176.17 & 5.29 & 2.13 & 2.84 & * \\
\hline 30 & A-labialis superior (mm) & 21.7 & 3.2 & 21.95 & 2.9 & 0.25 & 1.65 & \\
\hline 31 & E line-labialis superior $(\mathrm{mm})$ & -2.82 & 2.12 & -3.23 & 2.01 & -0.41 & 1.15 & \\
\hline 32 & E line-labialis inferior (mm) & -1.24 & 2.97 & -0.92 & 3.08 & 0.32 & 0.67 & \\
\hline 33 & Labialis superior-RL2 (mm) & 81.57 & 7.91 & 81.55 & 7.25 & -0.03 & 1.99 & \\
\hline 34 & Labialis inferior-RL2 (mm) & 75.04 & 7.91 & 76.39 & 7.48 & 1.35 & 1.89 & * \\
\hline 35 & Lip strength (mm) & 3.9 & 2.85 & 2.79 & 2.69 & -1.15 & 1.84 & * \\
\hline
\end{tabular}

Table 4: Changes and Comparisons of Pretreatment and Postreatment Values within the Treatment Group.

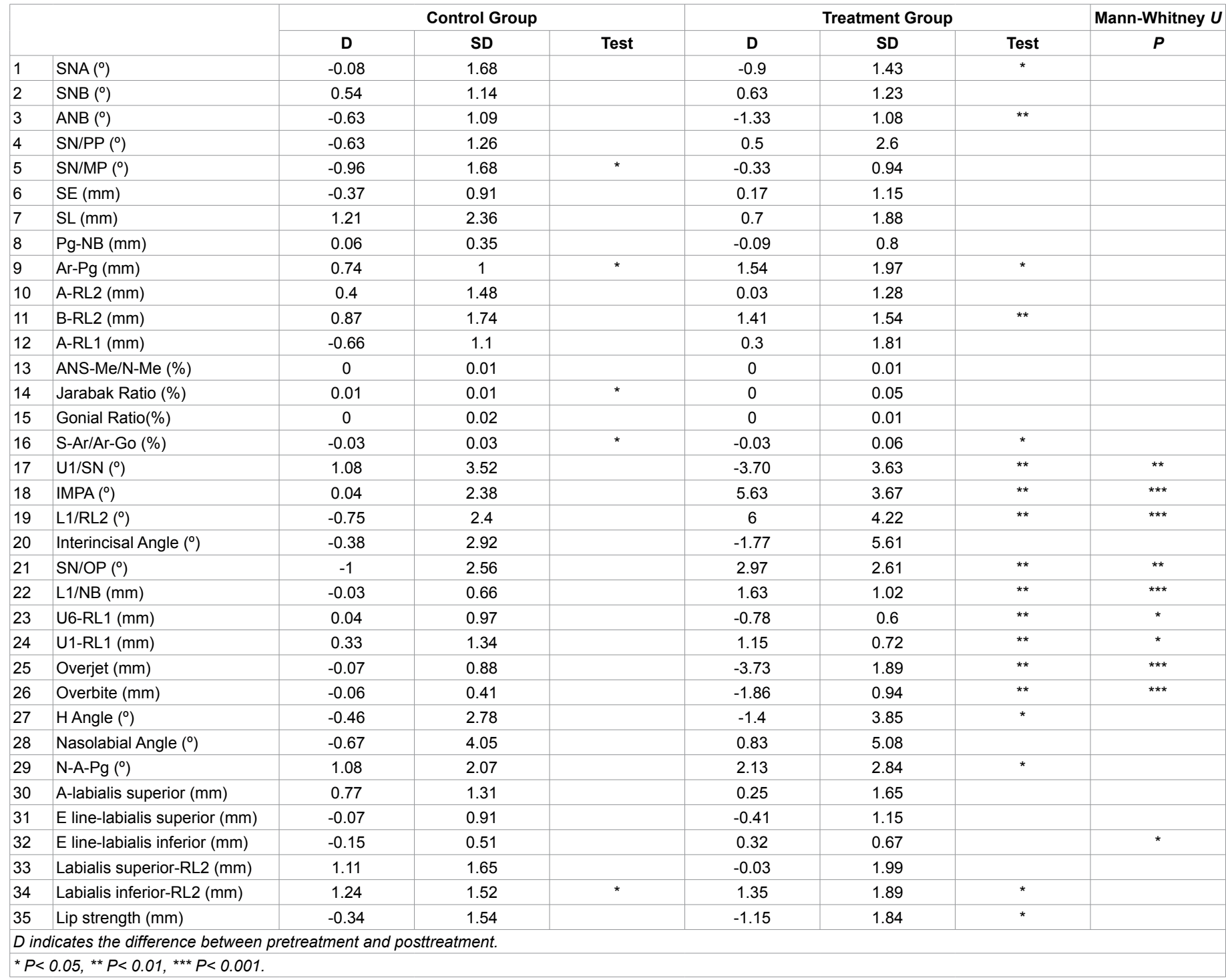

Table 5: Comparison of Dental, Skeletal, and Soft-tissue Changes of the Control and Treatment Groups Related to Treatment 


\section{Soft Tissue Changes}

The improvement in the soft tissue profile was attained by the reflection of the dentoskeletal changes. The significant differences related to SUS ${ }^{2}$ application are seen in Table 4 . The increase in the Labialis inferior-RL2 distance $(1.35 \mathrm{~mm}, p<0.05)$ showed that the lower lip moved forward as the lower incisors protruded. On the other hand, the decrease in the lip strength $(1.15 \mathrm{~mm}, p<0.05)$ and $\mathrm{H}$ angle $\left(-1.4^{\circ}\right.$, $p<0.05)$ revealed the backward movement of the upper lip due to the retroclination of the upper incisors. Even though other parameters indicating the position of the upper lip were found insignificant, they all confirmed this finding. However when two groups were compared, the only parameter that was found statistically significant was the distance of the lower lip from E-line (Table 5). This finding corroborated the forward movement of the lower lip due to the proclination of the lower incisors.

\section{Discussion}

This study was designed to evaluate the dentofacial changes induced by the Sabbagh Universal Spring (SUS ${ }^{2}$ ) used in mandibular retrognathic patients. A Class I molar relationship was achieved, and overjet and overbite were decreased in all of the patients (Figures 5 and $6)$.

The study sample was consisted of 15 patients who were at the postpubertal growth period. This group who had normal or lowangle growth pattern was preferred since they could both benefit from the minimal residual growth and would require less time for posttreatment retention. In the treatment group a Class I or edgeto-edge overcorrection was attained in all of the patients. The results indicated that this Class II correction was obtained through maxillary and mandibular dentoalveolar changes and no statistically significant skeletal effects were recorded both sagittally and vertically (Figure 7). In the treatment group even though a decrease was seen at the SNA angle, the comparison of both groups revealed no statistically significant difference, showing that the appliance had no effect on restraining the forward growth of the maxilla. This finding is in accordance with the results of Weiland and Bantleon [20], Aelbers and Dermaut [21] and Karacay et al. [22] On the other hand, Valant and Sinclair [9] and Pancherz [23] reported decrease at SNA angle that revealed the high-

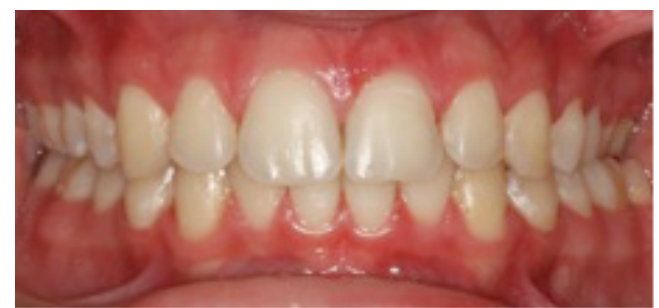

Figure 5: Intraoral photos taken at end of the treatment.

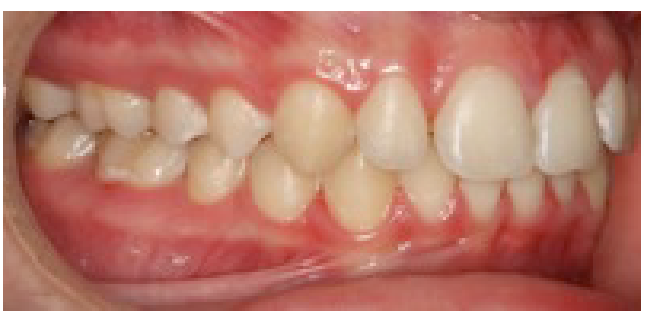

Figure 6: Intraoral photos taken at end of the treatment.

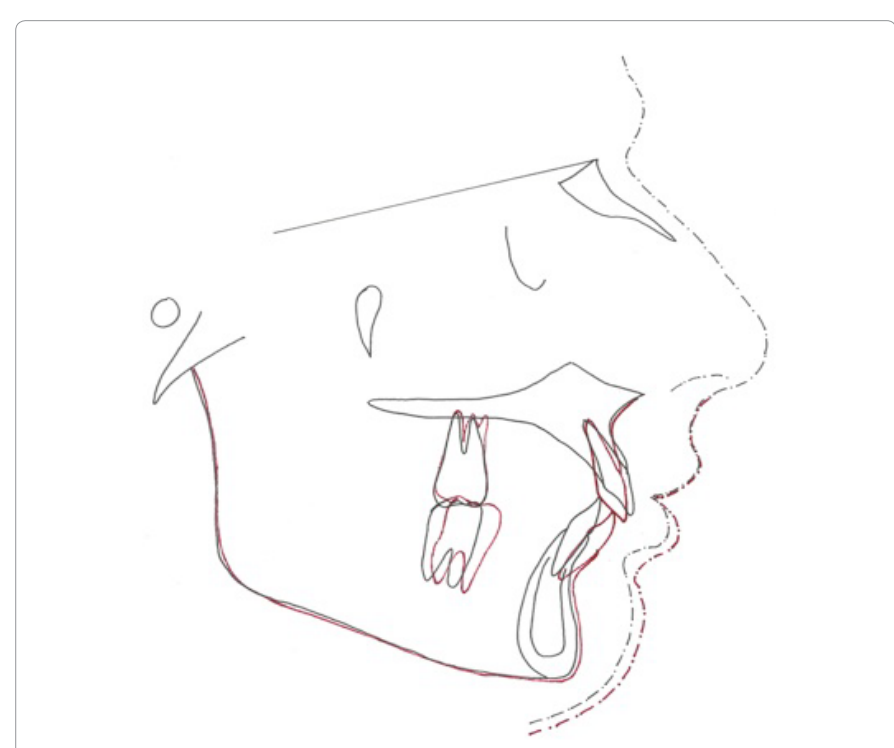

Figure 7: The total superimposition of lateral cephalometric radiograms on Sella-Nasion at Sella: black lines, before application and green lines, after removal.

pull headgear effect of Herbst appliance on growing patients. This difference between our results may be related to age variation of the sample groups and different treatment mechanics.

Similar to maxilla, no significant effect was found on the mandible. During SUS ${ }^{2}$ therapy, the increase in the Ar-Pg distance may be related to the anterior repositioning of the mandible rather than forward growth. Küçükkeleş et al. [24] reported that the reason for the increase might be due to the change in the pogonion location whereas; Chen et al. [25] proclaimed the reason for this increase as the backward and upward relocation of articulare point during functional treatment. Likewise, the increase in B-RL2 distance might be attributed to the mesial location of pogonion in the treatment group.

In our study, no vertical skeletal changes were observed. This finding confirmed that the appliance did not elongate the facial height in late adolescent patients and it is consistent with the results of other investigators $[14,20,23,26]$. Hence since vertical control was preserved, we think that this appliance can be used in high-angle cases. However, knowing that retrusion of the upper incisors may cause an increase at the gingival display; high-angle patients without high smile line should be chosen.

Dentoalveolar changes were in accordance with previous studies regarding fixed functional appliances $[12,14,20,26]$. Even though the highpull headgear effect of the appliance did not cause any skeletal change on the maxilla, the maxillary first molars were tipped distally as a result of the force vector that passes below and behind the center of resistance of the upper dentoalveolar arch. Since the dentition was blocked together, this force also influenced the maxillary incisors through archwire. The changes in U1/SN angle and U1-RL1 distance showed that the upper incisors retruded and extruded significantly. In our study, in order to prevent these unwanted teeth movement, bands were placed on second molars and a transpalatal arch was utilized to preserve the anchorage in the posterior region.

As for the lower incisors, the anterior tipping were apparent similar to the studies with different functional appliances that revealed this inclination to various degrees [10,12-14,26,27]. The change in the 
parameters related to mandibular incisors indicated that these teeth intruded with labial tipping. This significant proclination may be due to the anterior direction of the force generated by the inner spring. Besides using negative torqued lower incisor brackets or having lingual crown torque at the lower anterior segment, full ligation of the lower dental arch and reducing the force setting are possible options to prevent the protrusion of the lower incisors.

The correction of the overjet was achieved both by the retrusion of the upper incisors and protrusion of the lower incisors. The vertical component of these tipping movements also led to a development of the bite. Previous functional therapy studies also pointed out to significant decreases in overbite and overjet $[12,14,20,23,26,28]$. The combination of these adverse movements of the upper and lower teeth both in sagittal and vertical directions also produced a $2.97^{\circ}$ clockwise rotation of the occlusal plane. Other investigators reported similar effects on the occlusal plane in their studies $[12,14,20,23,26]$.

The changes related to the soft-tissue profile were to a lesser extent than the dentoalveolar changes. In the treatment group, the lip strength decreased significantly as a result of the retrusion of the upper lip following the backward tipping of the upper incisors and also, the lower lip was no longer captured behind the upper incisors. Moreover, the proclined lower incisors supported the lower lip. When the two groups compared, the only statistically significant increase was found in the E line-Lab. inf. distance as the lower lip moved forward. Consequently, the changes related to the soft tissue profile were limited, so $\mathrm{SUS}^{2}$ therapy may not compensate the outcome that can be achieved by orthognathic surgery in Class II adult patients. Similar soft-tissue changes were attained from previous studies [26-29].

The findings of this clinical pilot study show that the correction of mandibular retrognatia by the SUS ${ }^{2}$ appliance in post peak growth period was achieved by only dentoalveolar changes and no skeletal difference that forced the mandible to posture and function in a forward position was obtained. Thus, this appliance can be an acceptable substitute to Class II elastics for patients who appear to be noncompliant.

Since no comprehensive study about this appliance have been documented yet, albeit the small study sample size, the results still provide an indication on the effects of the appliance on dentofacial structures. These significant dentoalveolar changes obtained necessitate further clinical studies with an extended sample size that will reveal the long-term TMJ effects and stability of the appliance used in late adolescence.

\section{Conclusions}

- Correction of Class II malocclusion by the SUS ${ }^{2}$ appliance in post peak growth period was achieved by only dentoalveolar changes.

- No vertical skeletal changes were observed.

- The changes related to the soft tissue profile were limited.

\section{References}

1. Sassouni VA (1969) A Classification of skeletal facial types. Am J Orthod 55: 109-123.

2. Mc Namara JA Jr (1981) Components of Class II malocclusion in children 8-10 years of age. Angle Orthod 51: 177-202.

3. Bass NM (1982) Dentofacial orthopaedics in the correction of Class II malocclusion. $\mathrm{Br} \mathrm{J}$ Orthod 9: 3-31

4. Jena AK, Duggal R (2010) Treatment effects of Twin-Block and Mandibular Protraction Appliance-IV in the correction of Class II malocclusion. Angle
Orthod 80: 485-491.

5. Pancherz $\mathrm{H}$, Haag U (1985) The Herbst appliance-its biologic effects and clinical use. Am J Orthod 87: 1-20.

6. Pancherz H, Hansen K (1986) Occlusal changes during and after Herbst treatment. A cephalometric investigation. Eur J Orthod 8: 215-228.

7. Pancherz H, Ruf S, Kohlhas P (1998) "Effective condylar growth" and chin position changes in Herbst treatment: a cephalometric roentgenographic longterm study. Am J Orthod Dentofacial Orthop 114: 437-446.

8. Mc Namara JA, Howe RP, Dischinger TG (1990) A comparison of the Herbst and Frankel appliances in the treatment of Class II malocclusion. Am J Orthod Dentofacial Orthop 98: 134-143.

9. Valant JR, Sinclair PM (1989) Treatment effects of the Herbst appliance. Am J Orthod Dentofacial Orthop 95: 138-147.

10. Konik M, Pancherz H, Hansen K (1997) The mechanism of Class II correction in late Herbst treatment. Am J Orthod Dentofacial Orthop 112: 87-91.

11. Blackwood HO (1991) Clinical management of the Jasper Jumper. J Clin Orthod 25: 755-760.

12. Cope JB, Buschang PH, Cope DD, Parker J, Blackwood HO (1994) Quantitative evaluation of craniofacial changes with Jasper Jumper therapy. Angle Orthod 2: 113-122.

13. Mills CM, McCulloch KJ (1997) Case report: modified use of the Jasper Jumper appliance in a skeletal Class II mixed dentition case requiring palatal expansion. Angle Orthod 4: 277-282

14. Covell DA, Trammell DW, Boero RP, West R (1999) A cephalometric study of Class II division 1 malocclusion treated with the Jasper Jumper appliance. Angle Orthod 69: 311-320.

15. Sabbagh A (2006) The Sabbagh Universal Spring. Mosby.

16. Rains MD, Nanda R (1982) Soft tissue changes associated with maxillary incisor retraction. Am J Orthod Dentofacial Orthop 81: 481-488.

17. Tomlak DJ, Piecuch JF, Weinstein S (1984) Morphologic analysis of upper lip area following maxillary osteotomy via the tunneling approach. Am J Orthod Dentofacial Orthop 85: 488-493.

18. Talass MF, Talass L, Baker RC (1987) Soft tissue profile changes resulting from retraction of maxillary incisor. Am J Orthod Dentofacial Orthop 91: 385-394.

19. Firouz M, Zernik J, Nanda R (1992) Dental and orthopedic effects of high pull headgear in treatment of Class II division 1 malocclusion. Am J Orthod Dentofacial Orthop 102: 197-205.

20. Weiland FJ, Bantleon HP (1995) Treatment of Class II malocclusions with the Jasper Jumper appliance. A preliminary report. Am J Orthod Dentofac Orthotop 108: 341-350.

21. Aelbers CMF, Dermaut LR (1999) Orthopadie in der Orthodontie-Ein Literaturüberblick. Inf Orthod Kieferorthop 31: 65-79.

22. Karacay S, Akin E, Olmez H, Gurton AU, Sagdi D (2006) Forsus Nitinol Fla Spring and Jasper Jumper Corrections of Class II division 1 Malocclusions. Angle Orthod 76: 666-672.

23. Pancherz $H$ (1982) The mechanism of Class II correction in Herbst appliance treatment. Am J Orthod Dentofac Orthop 82: 104-113.

24. Küçükkeleş N, İlhan I, Orgun A (2007) Treatment Efficiency in Skeletal Class II Patients Treated with the Jasper Jumper. Angle Orthod 77: 449-456.

25. Chen JY, Will LA, Niederman R (2002) Analysis of efficacy of functional appliances on mandibular growth. Am J Orthod Dentofac Orthop 122: 470-476.

26. Nalbantgil D, Arun T, Sayınsu K, Işık F (2005) Skeletal, Dental and Soft Tissue Changes Induced by the Jasper Jumper appliance in late adolescence. Angle Orthod 75: 426-436.

27. Weiland FJ, Droschl H (1996) Treatment of a Class II, Division 1 malocclusion with the Jasper Jumper: a case report. Am J Orthod Dentofac Orthop 109: 1-7.

28. Ruf S, Pancherz H (1998) Dentoskeletal effects and facial profile changes in young adults treated with the Herbst appliance. Angle Orthod 69: 239-246.

29. Schweitzer M, Pancherz H (2001) The incisor-lip relationship in Herbst/ Multibracket appliance treatment of Class II division 2 malocclusions. Angle Orthod 71: 358-363. 